\title{
Haemostatic action of a topical foam- based patch (VELSEAL-T) in haemophiliac patients with external bleeding
}

Anupam Dutta, Taniya Sarkar Dutta, Anup Kumar Das, Pranoy Dey

Introduction: Haemophilia is an X-linked congenital bleeding disorder due to deficiency of coagulation factor VIII (in haemophilia A) or factor IX (in haemophilia B) caused by mutations of the respective clotting factor genes. Treatment involves the administration of an appropriate dose of factor concentrate, as soon as possible, in the event of any bleeding episode. In low-resource settings, such as Northeast India, where factor concentrates are not widely available, people with haemophilia $(\mathrm{PwH})$ may bleed profusely even from trivial external injuries, warranting transfusion of blood or blood products. We previously reported on the use of a low cost, foambased haemostatic patch to treat an external bleed in a single patient. In this study, we investigated its use to treat a range of external injuries in $\mathrm{PwH}$ presenting at Assam Medical College and Hospital. Method: Over 24

ANUPAM DUTTA

Assistant Professor, Department of Medicine, Assam

Medical College and Hospital, Dibrugarh, India. Email:

dranupamdutta80@gmail.com

TANIYA SARKAR DUTTA

Paediatric Registrar, Department of Paediatrics, Assam

Medical College and Hospital, Dibrugarh, India

ANUP KUMAR DAS

Professor, Department of Medicine, Assam Medical

College and Hospital, Dibrugarh, India

PRANOY DEY

Professor, Department of Paediatrics, Assam Medical

College and Hospital, Dibrugarh, India

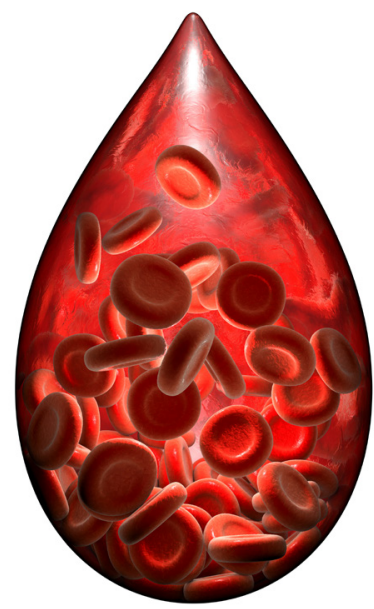

The use of a haemostatic patch to treat external injuries in people with haemophilia presenting at a hospital in Northeast India suggests that it may be a beneficial first aid dressing, particularly in low resource settings where access to factor concentrates is limited.

months, eligible $\mathrm{PwH}$ with external injuries attending our haemophilia clinic were treated with a topical haemostatic patch (VELSEAL-T) at the target bleeding site. The time to cessation of bleeding was recorded and the wound sites evaluated after haemostasis to monitor efficacy and safety. Results: Out of 72 individuals with bleeding disorders who volunteered to participate, 59 cases of external bleeding in $48 \mathrm{PwH}$ were eligible for inclusion in the study. Nine (15.3\%) had aberration wounds, 24 (40.7\%) cut wounds, 21 (35.6\%) tooth and/or gum bleeding and five $(8.4 \%)$ bleeding from puncture wounds. The average time

This is an Open Access article distributed under the terms of the Creative Commons Attribution-NonCommercial-NoDerivs License (https://creativecommons.org/licenses/by-nc-nd/3.0/) which permits use and distribution in any medium, provided the original work is properly cited, the use is non-commercial, and no modifications or adaptations are made. Copyright is retained by the authors. 
required for achievement of haemostasis was 9.9 $( \pm 4.7)$ minutes. Aberration wounds required the least amount of time for haemostasis at $7.3( \pm 4.4)$ minutes. Cut wounds required a mean time of $8.5( \pm 2.9)$ minutes; puncture wounds required $9.0( \pm 3.1)$ minutes; gum bleeding required the longest time to achieve haemostasis with a mean of $12.7( \pm 5.6)$ minutes. Conclusion: The use of this topical haemostatic patch has been shown to be beneficial in the treatment of external injuries in $\mathrm{PwH}$, and provides a good treatment option in resource-constrained areas. A larger controlled study would be helpful to further investigate its efficacy and safety.

Keywords: Haemophilia, External injury, Haemostatic patch, India

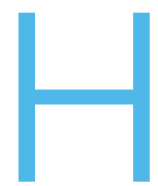

aemophilia is an X-linked congenital bleeding disorder due to deficiency of coagulation factor VIII (in haemophilia A) or factor IX (in haemophilia B) caused by mutations of the respective clotting factor genes. People with severe haemophilia generally present with spontaneous joint and intramuscular bleeds, causing musculoskeletal deformities, resulting in difficulty in gait and movement. Though not very common, they may also present with uncontrolled bleeding from cut wounds and other external injuries. Pressure bandages are frequently used as first aid and oral tranexamic acid is advocated in the majority of cases. The ideal treatment for any bleeding episode in people with haemophilia $(\mathrm{PwH})$ involves the administration of an appropriate dose of factor concentrate as soon as possible. However, factor concentrates are costly and not easily affordable or accessible by all $\mathrm{PwH}$, especially in developing countries like India. Although recommendations have been made for at least a low-dose regimen of primary prophylaxis in severe haemophilia ${ }^{[1]}$, high costs prevent this and $\mathrm{PwH}$ are generally treated on demand ${ }^{[2]}$.

In Northeast India, a remote region where resources are scarce, $\mathrm{PwH}$ may have to travel long distances to receive proper treatment and may bleed profusely as a result of even minor traumas. In the past, many $\mathrm{PwH}$ in the region have bled profusely from external injuries, warranting transfusion of blood or blood products. $\mathrm{PwH}$ have been treated at Assam Medical College and Hospital for several years and we have described their frequent bleeds, clinical presentations and complications ${ }^{[3,4]}$. In addition to spontaneous joint and intramuscular bleeds, causing musculoskeletal deformities, many $\mathrm{PwH}$ present at the clinic with bleeding from external injuries. Although pressure gauze and ice packs have traditionally been recommended and used, on many occasions these have not been adequate in managing bleeding. Studies have suggested that fibrin glue and chitosan-based dressings (CBDs) could be useful local haemostatic agents in $\mathrm{PwH}$. Rodriguez-Merchan describes their use, for example, in surgical wounds with a higher potential to bleed more than expected (i.e. in patients with inhibitors), and also in circumcision, dental extraction, and some orthopaedic procedures (e.g. surgical removal of pseudotumours) ${ }^{[5]}$. Haemostatic dressings, such as those with chitosan, have also been recommended for the treatment of external/accessible bleeds, especially among paediatric patients with a bleeding tendency ${ }^{[6]}$. We previously described the use of a novel haemostatic patch (VELSEAL-T) to treat a case of profuse bleeding from an injury to the forehead in a 36-year-old $\mathrm{PwH}$ at a time when logistical issues meant that other forms of treatment were not available ${ }^{[7]}$. We concluded that VELSEAL-T could be used safely and is a cost-effective treatment in stopping external bleeding in haemophilia patients. In the study reported here, we investigated whether this haemostatic patch could be more widely used to treat different types of external bleeding effectively and safely in $\mathrm{PwH}$ presenting at Assam Medical College and Hospital.

\section{METHOD}

All $\mathrm{PwH}$ above five years of age attending the haemophilia centre in our hospital were invited to participate in this single-arm (uncontrolled), prospective, interventional study, after having the mechanism of action of the product explained to them. Institutional ethical clearance was obtained and $\mathrm{PwH}$ (or their legal guardian) gave written consent in their regional language before participating in this study. $\mathrm{PwH}$ who presented with a medical emergency needing urgent intervention, factors, blood or other blood products, and subjects unwilling to participate were excluded from the study. The study period was 24 months.

\section{The material: VELSEAL-T}

VELSEAL-T is a sterile (gamma irradiated) ready-touse topical haemostatic patch for external control of traumatic bleeding. Its constituents include chitosan, gelatine, bovine thrombin, tranexamic acid, and calcium chloride. Gelatine and chitosan form porous foam, which provides a large surface area for blood clotting procedure to occur. While thrombin and calcium 
chloride incorporated into the patch directly help in clotting and thrombus formation, tranexamic acid, an anti-fibrinolytic agent, prevents the dissolution of the clot. The manufacturers report a mean time of four minutes to achieve haemostasis in traumatic or surgical wounds, and both venous and arterial bleeds after angiography/angioplasty. Taking account of the fact that our target subjects have bleeding disorders, we fixed our primary end point arbitrarily at three times the manufacturers' reported mean.

\section{Data collection}

$\mathrm{PwH}$ who presented to our hospital with external bleeding were attended at the earliest opportunity by our investigators and caregivers of the haemophilia centre, and the wound was evaluated. Wounds were divided into four categories: aberrations (partial skin thickness wound involving only the epidermis to deep dermis), cuts or laceration injuries (a break or opening in the skin going below dermis), tooth and gum bleeding (oral bleeding from dental or gingival tissue), and puncture wounds (injury caused by a pointed object that pierces or penetrates the skin). Baseline data was recorded, and the wound was further evaluated with regard to whether surgical intervention was needed or not. Where surgical intervention was note required, the VELSEAL-T haemostatic patch was applied at the site of the bleeding injury and the time was recorded using a stopwatch. The patch was removed as soon as the bleeding stopped and clotting was seen. In the case of re-bleeding, the patch was applied again. The site of wound was evaluated at the time of cessation of bleeding and again at 20 minutes, two hours and four hours after the application of VELSEAL-T to monitor the efficacy and safety of the product. The primary endpoint was to record the proportion of cases with successful cessation of bleeding within 12 minutes (arbitrarily) after application of VELSEAL-T at the target bleeding site. Secondary endpoints were the average time taken to control bleeding, and the proportion of subjects demonstrating sensitivity reaction to the VELSEAL-T material or infection at the application site.

\section{RESULTS}

Seventy-two individuals with haemophilia and other rare bleeding disorders attending the haemophilia centre at Assam Medical College and Hospital, volunteered to be part of this study. Over a period of 24 months, 50 individuals with haemophilia presented to us with 61 episodes of various external injuries. Two patients with severe injuries needed surgical and orthopaedic interventions along with urgent factor replacement, hence they were excluded from the study. The remaining 48 individuals had 59 episodes of injury, with nine $\mathrm{PwH}$ presenting on two separate occasions and one presenting three times for different injuries (Table 1). Each of the 59 episodes of external injury were studied as a single case. Out of 59 cases of VELSEAL-T use, nine (15.3\%) were aberration wounds, 24 (40.7\%) were cut wounds, 21 (35.6\%) involved gum bleeding, and five (8.4\%) were bleeding from puncture wounds. The mean age of those presenting was 17 years; the youngest was

Table 1. Demographics of the study group $(n=48)$

\begin{tabular}{|l|l|l}
\hline Haemophilia A & NUMBER (N) & PERCENTAGE (\%) \\
\hline Mild (factor level 5-50\%) & 42 & $87.5 \%$ \\
\hline Moderate (factor level 1-5\%) & 5 & $10.4 \%$ \\
\hline Severe (factor level $<1 \%)$ & 7 & $14.6 \%$ \\
\hline Haemophilia B & 30 & $62.5 \%$ \\
\hline$\quad$ Mild (factor level 5-50\%) & 5 & $10.4 \%$ \\
\hline Moderate (factor level 1-5\%) & 0 & $2.1 \%$ \\
\hline Severe (factor level $<1 \%)$ & 1 & $8.3 \%$ \\
\hline Other bleeding disorders (factor X deficiency) & 4 & $2.1 \%$ \\
\hline Children (under 18 years) & 1 & $58.3 \%$ \\
\hline Adults ( 18 years and above) & 28 & $41.7 \%$ \\
\hline Total number of external injuries & 20 & $79.2 \%$ \\
\hline PwH presenting with a single episode of external injury & 59 & $18.7 \%$ \\
\hline PwH presenting with two episodes of external injury & 38 & $2.1 \%$ \\
\hline PwH presenting with three episodes of external injury & 9 & 1 \\
\hline
\end{tabular}


Table 2. Bleeding in each wound type (total number of wounds $=59$ )

\begin{tabular}{|c|c|c|c|}
\hline WOUND TYPE & NUMBER (PERCENTAGE) & $\begin{array}{l}\text { NUMBER (PERCENTAGE) } \\
\text { ACHIEVING PRIMARY } \\
\text { OUTCOME }\end{array}$ & $\begin{array}{l}\text { PERCENTAGE OF } \\
\text { WOUND TYPE ACHIEVING } \\
\text { PRIMARY OUTCOME }\end{array}$ \\
\hline Aberration & $9(15.3 \%)$ & $8(17.4 \%)$ & $88.9 \%$ \\
\hline Cut or laceration & $24(40.7 \%)$ & $22(47.8 \%)$ & $91.7 \%$ \\
\hline Tooth and or gum bleeds & $21(35.6 \%)$ & $12(26.1 \%)$ & $57.1 \%$ \\
\hline Puncture & $5(8.4 \%)$ & $4(8.7 \%)$ & $80 \%$ \\
\hline
\end{tabular}

four years and eldest was 54 years. The mean size of injury was $1.6( \pm 1) \mathrm{cm}$ and the average time required for achievement of haemostasis was 9.9 minutes.

Out of 59 cases, 46 (78\%) achieved the primary endpoint of successfully ceasing haemorrhage within 12 minutes after application of VELSEAL-T at the target bleeding site. This endpoint was not achieved in $13(22 \%)$ cases. Of these, two were cut injuries (one deep cut to the left thigh and one in the big toe following trauma), one was an aberration to the right elbow following a fall, and one was a puncture wound for drainage of a haematoma. The other nine cases involved tooth and gum bleeding. The results are summarised in Table 2.

The mean size of the injury in puncture wounds was $1 \mathrm{~cm}$, in gum bleeds $1( \pm 0.2) \mathrm{cm}$, in cut wound $2( \pm 1) \mathrm{cm}$, and in aberration wounds $2.2( \pm 1.2) \mathrm{cm}$. Aberration wounds required the least amount of time for haemostasis at $7.3( \pm 4.4)$ minutes. Cut wounds required a mean time of $8.5( \pm 2.9)$ minutes and puncture wounds required a mean time of $9.0( \pm 3.1)$ minutes. Patients presenting with gum bleeding required the longest time to achieve haemostasis, with a mean of $12.7( \pm 5.6)$.

One patient complained of itching at the site of application of VELSEAL-T, which improved later after removal. None of the patients developed any serious allergy or infection at the site of application.

On a five point Likert scale, where 1 stands for easy/good response by the investigators and 5 stands for difficult/bad, the overall mean score for ease of handling VELSEAL-T was $1.6( \pm 0.9)$, for ease of application to site $2.0( \pm 1.3)$, and for conformance to tissue surface $1.7( \pm 1.0)$. The overall performance of the device was rated $1.6( \pm 0.8)$. The scores of all these parameters were lowest for aberration wounds, followed by cut wounds and puncture wounds (Table 3). The scores were worst for tooth and gum bleeds, with a mean score of $3.0( \pm 1.6)$ for ease of application to site, $2.4( \pm 1.4)$ for conformance to tissue surface, and 2.3 ( \pm 1.1$)$ for overall performance.

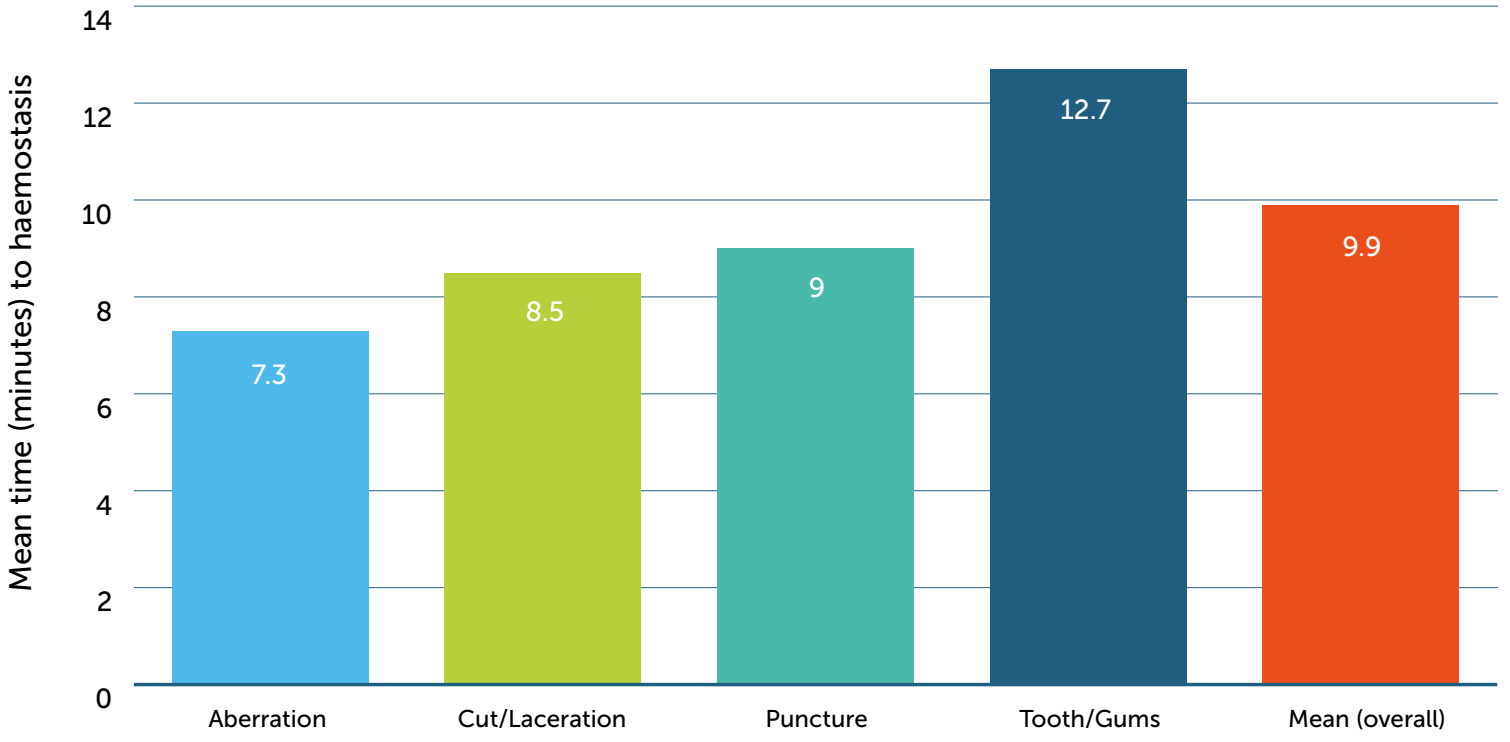


Table 2. Bleeding in each wound type (total number of wounds $=59$ )

\begin{tabular}{|c|c|c|c|c|c|}
\hline & $\begin{array}{l}\text { ABRASION } \\
(\mathrm{N}=9)\end{array}$ & $\begin{array}{l}\text { CUT OR } \\
\text { LACERATION } \\
(\mathrm{N}=24)\end{array}$ & $\begin{array}{l}\text { TOOTH OR } \\
\text { GUM BLEEDING } \\
(\mathbf{N}=21)\end{array}$ & $\begin{array}{l}\text { PUNCTURE } \\
(\mathrm{N}=5)\end{array}$ & P-VALUE \\
\hline Age of patient* & $18.78( \pm 6.6)$ & $21.67( \pm 9.7)$ & $8.0( \pm 5.8)$ & $23.8( \pm 18.2)$ & $<0.001$ \\
\hline Size of injury $(\mathrm{cm})^{\#}$ & $2.2( \pm 1.2)$ & $2.0( \pm 1.0)$ & $1.0( \pm 0.2)$ & $1.0( \pm 0.0)$ & 0.003 \\
\hline $\begin{array}{l}\text { Time to achieve } \\
\text { haemostasis (minutes) }{ }^{\#}\end{array}$ & $7.3( \pm 4.4)$ & $8.5( \pm 2.9)$ & $12.7( \pm 5.6)$ & $9.0( \pm 3.1)$ & 0.011 \\
\hline Ease of handling (1 to 5$)^{\#}$ & $1( \pm 0)$ & $1.1( \pm 0.3)$ & $2.3( \pm 1.2)$ & $1.6( \pm 0.5)$ & $<0.001$ \\
\hline $\begin{array}{l}\text { Ease of application to the } \\
\text { site ( } 1 \text { to } 5)^{\#}\end{array}$ & $1.6( \pm 0.9)$ & $1.4(v 0.6)$ & $3.0( \pm 1.6)$ & $1.6( \pm 0.9)$ & 0.001 \\
\hline $\begin{array}{l}\text { Conformance to tissue } \\
\text { surface ( } 1 \text { to } 5)^{\#}\end{array}$ & $1.0( \pm 0)$ & $1.3(v 0.5)$ & $2.4( \pm 1.4)$ & $1.6( \pm 0.9)$ & 0.003 \\
\hline $\begin{array}{l}\text { Overall performance of } \\
\text { the device ( } 1 \text { to } 5)^{\#}\end{array}$ & $1.2( \pm 0.4)$ & $1.3( \pm 0.4)$ & $2.3( \pm 1.1)$ & $1.4( \pm 0.5)$ & $<0.001$ \\
\hline
\end{tabular}

* $p$ value calculated by ANOVA; * $p$ value calculated by ANOVA (age adjusted)

\section{DISCUSSION}

Since ancient times, many different materials have been used to treat wounds in an attempt to stop bleeding, absorb exudates and promote healing, including honey, animal oils or fat, cobwebs, mud, leaves, sphagnum moss, and animal dung ${ }^{[8]}$. Of these substances, with the exception of honey, none have shown promising results. Lawrence, Piskozub, and Thomas et al. described the structure and absorbency of dressing materials several decades ago ${ }^{[9-11]}$. Presentday technologies and innovation have produced wider range of dressing materials. Gauze is the most widely used dressing material and is available in various forms, including gauze impregnated with substances such as petroleum, iodine, bismuth, and zinc.

Foam dressings, made from a polyurethane base, are permeable to both gases and water vapour. Their hydrophilic properties allow high absorption and provide thermal insulation ${ }^{[12]}$. Hydrogels are complex hydrophilic organic cross-linked polymers, consisting of an $80-90 \%$ water base, and can absorb an amount of fluid by swelling, thereby donating moisture to a dry wound. They facilitate autolytic debridement and maintain a moist wound environment that is thermally insulated ${ }^{[13]}$.

Hydrocolloid dressings contain an inner layer that is self-adhesive, gel-forming, and composed of hydrophilic colloid particles such as carboxymethylcellulose (CMC), pectin, gelatine, or an elastomer. This layer absorbs exudates and swells into a gel-like mass over the wound ${ }^{[13]}$. Hydrofibre dressings are made from sodium CMC and interact with serum or exudates to form a gel ${ }^{[14]}$. lodine-based dressings incorporate a natural, non-metallic element with established antimicrobial properties ${ }^{[15]}$, and charcoalbased dressings reduce wound odour by absorbing gases released by bacteria ${ }^{[13]}$.

Oxidised regenerated cellulose (ORC) is a bioabsorbable topical haemostatic woven material used to control bleeding. When applied to a bleeding surface, it forms a gelatinous mass, which eventually is absorbed within two to seven days. ORC may also exert moderate bacteriostatic effects in vitro due to creation of an acidic $\mathrm{pH}^{[16]}$. Hofman et al. conducted a smallscale study on chronic ulcers and concluded that the treatment was safe and promoted healing ${ }^{[17]}$.

VELSEAL-T is a chitosan-based dressing with gelatine, which falls under the category of foam dressing. Its hydrophilic property and porous nature help in absorbing large amount of blood, which is trapped inside the foam. Inside the porous spaces, the blood comes in contact with thrombin and calcium chloride incorporated into the patch. This facilitates clotting, which is the main motive behind using this material in haemophilia patients with excessive bleeding. The additional presence of tranexamic acid, an anti-fibrinolytic agent, reinforces the clot formation and results in rapid cessation of bleeding from the site of external injury or cut wounds.

Many of the commercially available haemostats have been associated with adverse safety ${ }^{[18]}$. Haemostats that are based on human- or animalderived components can lead to virus and disease transmission or elicit anaphylaxis ${ }^{[19-22]}$. Schuhmacher et al. studied a haemostatic patch in soft tissue bleeding during a variety of surgical procedures and found that haemostasis occurred within five minutes 


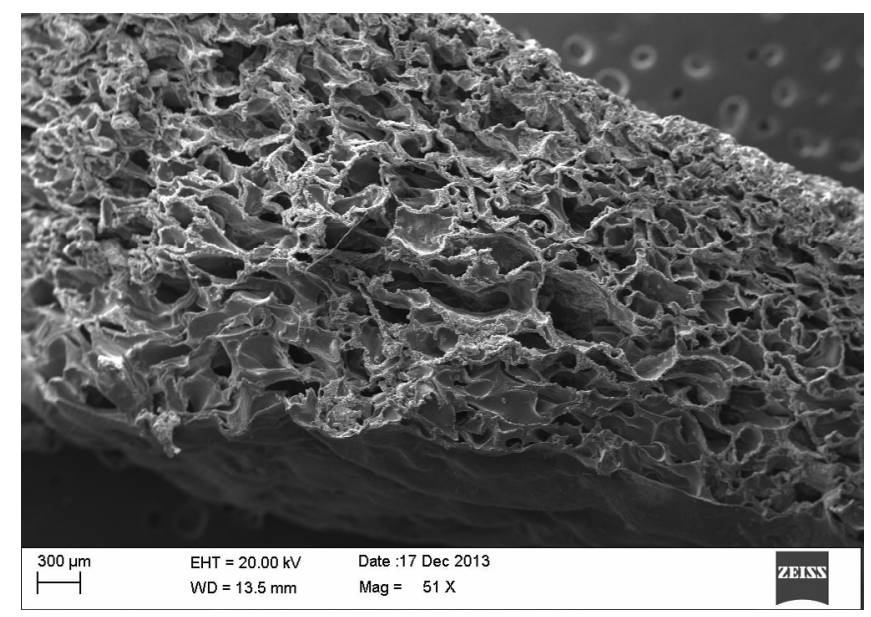

Figure 2. Electron microscope image of VELSEAL-T showing the porous spaces within the foam (reproduced with permission of Datt Mediproducts Pvt. Ltd)

in $29 / 30$ (96.7\%) subjects and within one minute in 21/30 (70.0\%) subjects ${ }^{[23]}$. Glineur et al. conducted a randomised controlled trial in 90 patients scheduled for cardiac or vascular surgery at 12 European institutions. This research group found that the median time to haemostasis was 1.5 minutes with a haemostatic patch (Veriset ${ }^{\mathrm{TM})}$, compared to 3.0 minutes with the fibrin sealant patch TachoSil ${ }^{\circledR}(p<0.0001)^{[24]}$. In our study, the mean time to achieve haemostasis, 9.9 minutes, is much higher than in previous published data.

A study by Kranokpiraksa et al. investigated an externally applied a percutaneous arterial closure device (PACD), chitosan-based HemCon Bandage (HCB), in sheep and found haemostasis at a mean time of $6.9( \pm 3.9)$ minutes ${ }^{[25]}$. Chitosan-based dressings are regarded as better haemostatic dressings for control of haemorrhage than current standards of care, especially in haemophilia ${ }^{[5]}$. In a small study by Misgav et al., five patients (median age two years) with severe bleeding disorders were treated with a topical chitosan-based dressing for a total of six bleeding episodes and showed good results ${ }^{[6]}$.

In our study oral bleeds due dental or gum pathology had the longest time to achieve haemostasis. Binet et al. describe a case of acquired haemophilia where oral bleeding was treated successfully with tranexamic acid mouthwash and recombinant human coagulation factor VIIa ${ }^{[26]}$. However, this course of treatment may not always be possible in settings such as ours due to the high costs associated with it. We had anticipated poorer results for tooth and gum bleeding for anatomical reasons, but as one in three patients presented with gum bleeding, the result was still better than not using the product at all.

\section{CONCLUSION}

Our study has shown significant benefit in the use of a topical haemostatic patch in external injuries in $\mathrm{PwH}$. It was effective in promoting haemostasis within 12 minutes in over three quarters of cases. Carrying out a larger placebo-controlled study with blinding would be a more statistically correct way of showing the significant benefit of using the VELSEAL-T haemostatic patch to treat external injuries in $\mathrm{PwH}$, although as haemophilia is a rare genetic disease, such a study may be difficult to conduct. Moreover, children with haemophilia are often overprotected by their parents, thereby avoiding ways of causing external injury as much as possible. They grow up to become more cautious and hence it is expected that external injury is not likely to be a common complication of haemophilia, when compared to spontaneous joint bleeds and intramuscular bleeds. However, in resource-constrained areas, in $\mathrm{PwH}$ not under prophylactic factor replacement and for $\mathrm{PwH}$ involved in outdoor activities, this topical haemostatic patch may be a very good first aid dressing material to prevent excessive bleeding from an external injury.

\section{ACKNOWLEDGMENTS}

We are thankful to all the members of Haemophilia Society Tinsukia Chapter for their help, Dipjyoti Baruah, Papari Borua, Akramul Wasim Haque, Dr Bhabani Shankar Dhal for assisting in the study, and Angsuman Baruah for statistical analysis.

The authors have advised no interests that might be perceived as posing a conflict or bias. Informed consent has been obtained from the participants in the study reported in this paper.

\section{ORCID}

Anupam Dutta (iD https://orcid.org/0000-0001-9520-5196 Taniya Sarkar Dutta (iD https://orcid.org/0000-0002-1739-2034 Anup Kumar Das (iD https://orcid.org/0000-0002-8097-4715 Pranoy Dey (iD https://orcid.org/0000-0002-8676-1358

\section{REFERENCES}

1. Sachdeva A, Gunasekaran V, Ramya HN, et al. Consensus statement of the Indian Academy of Pediatrics in diagnosis and management of hemophilia. Indian Pediatr 2018; 55: 582-90.

2. Gupta H, Dutta UP, Sengupta PP. The socioeconomic dimensions for the management of haemophilia in India: an empirical study. J Health Manag 2018; 20(1): 38-45. doi: 10.1177/097206341774699.

3. Dutta A, Dutta TS, Kar S, Kakati S, Dowerah P. Study on clinical presentation of factor deficient patients presenting to a tertiary care centre of North East India. Journal of Medical Science and Clinical Research 2016; 4(7): 11533-38. doi: 10.18535/ jmscr/v4i7.57. 
4. Dutta A, Dutta TS, Dey P. Clinical profile of haemophilia patients of Upper Assam - a hospital-based study. J Evol Med Dent Sci 2017;6(37):2990-93. doi: 10.14260/Jemds/2017/645

5. Rodriguez-Merchan EC. Local fibrin glue and chitosanbased dressings in haemophilia surgery. Blood Coagul Fibrinolysis 2012; 23(6): 473-6. doi: 10.1097/ MBC.0b013e3283555379.

6. Misgav M, Kenet G, Martinowitz U. Chitosan-based dressing for the treatment of external/accessible bleedings in children with bleeding tendency. J Pediatr Hematol Oncol 2014;36(2):140-2. doi: 10.1097/MPH.0b013e31828ac8b6

7. Dutta A, Das AK. Haemostasis action of VELSEAL-T in a haemophilia A patient with external bleeding. J Haem Pract 2018; 5(1): 4-7. doi: 10.17225/jhp00105.

8. Forrest RD. Early history of wound treatment. J R Soc Med 1982; 75: 198-205.

9. Lawrence JC. What materials for dressings? Injury 1982; 13: 500-12. doi: 10.1016/0020-1383(82)90166-8.

10. Piskozub ZT. The efficiency of wound dressing materials as a barrier to secondary bacterial contamination. $\mathrm{Br} \mathrm{J}$ Plast Surg 1968; 21(4): 387-401. doi: 10.1016/s00071226(68)80069-4.

11. Thomas S, Dawes C, Hay NP. Wound dressing materialstesting and control. Pharm J 1982; 228: 576-8.

12. Seaman S. Dressing selection in chronic wound management. J Am Podiatr Med Assoc 2002; 92(1): 24-33. doi: 10.7547/87507315-92-1-24.

13. Sood A, Granick MS, Tomaselli NL. Wound dressings and comparative effectiveness data. Adv Wound Care (New Rochelle) 2014; 3(8): 511-29. doi: 10.1089/wound.2012.0401.

14. Robinson BJ. The use of a hydrofibre dressing in wound management. J Wound Care 2000; 9(1): 32-4. doi: 10.12968/ jowc.2000.9.1.25941.

15. Thorn RM, Austin AJ, Greenman J, Wilkins JP, Davis PJ. In vitro comparison of antimicrobial activity of iodine and silver dressings against biofilms. J Wound Care 2009; 18(8): 343-6. doi: 10.12968/jowc.2009.18.8.43635

16. Spangler D, Rothenburger S, Nguyen $K$, et al. In vitro antimicrobial activity of oxidized regenerated cellulose against antibiotic resistant microorganisms. Surg Infect (Larchmt) 2003; 4(3): 255-62. doi: 10.1089/109629603322419599.

17. Hofman D, Wilson J, Poore S, Cherry G, Ryan T. Can Traumacel be used in the treatment of chronic wounds? J Wound Care 2000; 9(8): 393-6. doi: 10.12968/ jowc.2000.9.8.26280
18. Seyednejad $H$, Imani M, Jamieson T, Seifalian AM. Topical haemostatic agents. Br J Surg 2008; 95(10): 1197-225. doi: $10.1002 /$ bjs. 6357.

19. Hino M, Ishiko O, Honda Kl, et al. Transmission of symptomatic parvovirus B19 infection by fibrin sealant used during surgery. Br J Haematol 2000; 108(1): 194-5. doi: 10.1046/j.13652141.2000.01818.x

20. Pope M, Johnston KW. Anaphylaxis after thrombin injection of a femoral pseudoaneurysm: recommendations for prevention. J Vasc Surg 2000; 32(1): 190-1. doi: 101067/ mva.2000.106498

21. Tadokoro K, Ohtoshi T, Takafuji S, et al. Topical thrombininduced IgE-mediated anaphylaxis: RAST analysis and skin test studies. J Allergy Clin Immunol 1991; 88(4): 620-9. doi: 10.1016/0091-6749(91)90156-i.

22. Wai Y, Tsui V, Peng Z, Richardson R, Oreopoulos D, Tarlo SM Anaphylaxis from topical bovine thrombin (Thrombostat) during hae $\neg$ modialysis and evaluation of sensitization among a dialysis population. Clin Exp Allerg 2003; 33(12): 1730-4. doi: 10.1111/j.1365-2222-2003.01806.x.

23. Schuhmacher C, Pratschke J, Weiss S, et al. Safety and effectiveness of a synthetic hemostatic patch for intraoperative soft tissue bleeding. Med Devices (Auckl) 2015; 8: 167-74. doi: 10.2147/MDER.S79556.

24. Glineur D,Hendrikx M, Krievins D, et al. A randomized, controlled trial of Veriset ${ }^{\mathrm{TM}}$ hemostatic patch in halting cardiovascular bleeding. Med Devices (Auckl) 2018; 11: 65-75. doi: 10.2147/MDER.S145651.

25. Kranokpiraksa P, Pavcnik D, Kakizawa $H$, et al. Hemostatic efficacy of chitosan-based bandage for closure of percutaneous arterial access sites: An experimental study in heparinised sheep model. Radiol Oncol 2010; 44(2): 86-91. doi: 10.2478/v10019-010-0021-0.

26. Binet $Q$, Lambert $C$, Sacré L, Eeckhoudt S, Hermans $C$. Successful management of acquired hemophilia $A$ associated with bullous pemphigoid: a case report and review of the literature. Case Rep Hematol 2017; 2017: 2057019. doi: 10.1155/2017/2057019.

HOW TO CITE THIS ARTICLE:

Dutta A, Dutta TS, Das AK, Dey P. Haemostatic action of a topical foam-based patch (VELSEAL-T) in haemophiliac patients with external bleeding. J Haem Pract 2020; 7(1) 78-84. https://doi.org/10.17225/jhp00160.

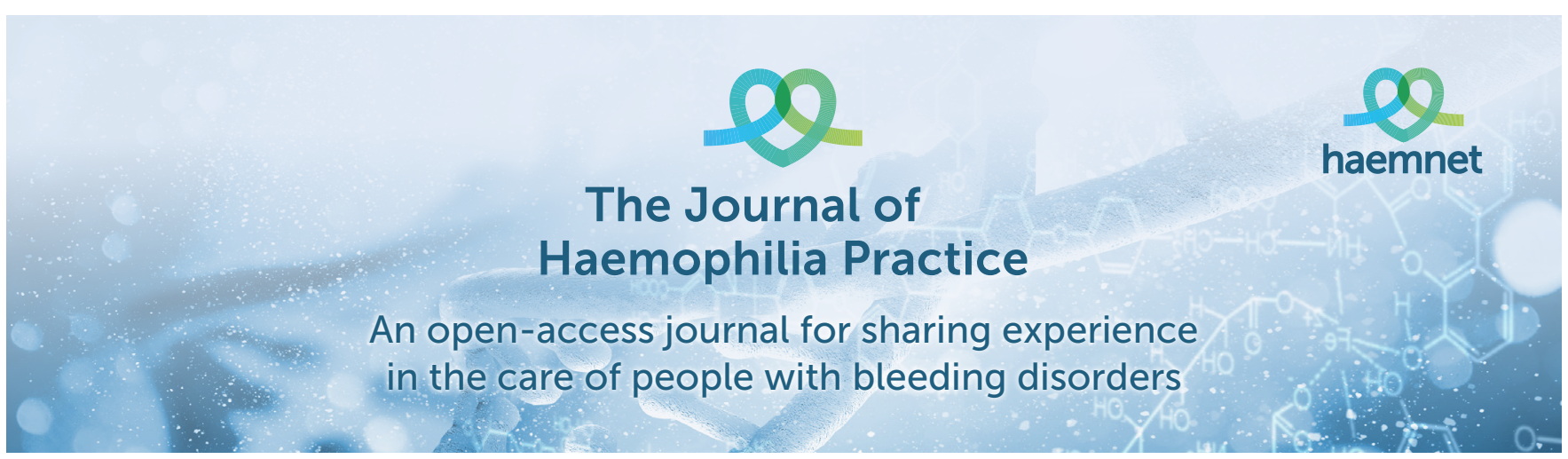

